\title{
A FAMÍLIA COMO FONTE PRIMÁRIA DE COMPORTAMENTO DO INDIVÍDUO EM SOCIEDADE: A IMPORTÂNCIA DA UNIDADE FAMILIAR PARA O DESENVOLVIMENTO DO ESTADO DE DIREITO
}

\author{
THE FAMILY AS PRIMARY SOURCE OF INDIVIDUALS BEHAVIOR IN \\ SOCIETY: THE IMPORTANCE OF THE FAMILY UNIT FOR THE DEVELOPMENT OF \\ THE RULE OF LAW
}

\author{
Gabriela Lauzid Kleinlein Lins ${ }^{1}$ \\ Nelson Pereira Medrado ${ }^{2}$
}

RESUMO: O presente artigo tem como objetivo explanar sobre o Princípio da Função Social da família e sua importância para o desenvolvimento do Estado. Tratar-se-á da relevancia da atuação do Estado na efetivação dos deveres e obrigações naturais da relação familiar e na preservação da dignidade da pessoa humana. Neste trabalho propõe-se uma análise imparcial a respeito da pertinência da comunidade familiar enquanto primeiro contato social da criança e do adolescente. A análise será por raciocínio dedutivo, a abordagem se dará de forma qualitativa e a técnica de pesquisa será por meio da pesquisa bibliográfica com breve análise histórico-social, consulta à legislação nacional e internacional, bem como a leitura de produções acadêmicas onde evidencia-se a preservação da Função Social da Família. Tratar-se-á dos Direitos Humanos, dos Direitos da Criança e do Adolescente, bem como da necessidade da Função Social da Família para sua concretização destes, usando como base comparativa os Estados Unidos e o Japão. Propõe-se trazer como base conceitual principalmente os doutrinadores do Direito Lucas Calderón, Dimas Messias de Carvalho. Serão usados os saberes e fundamentos da versada estudiosa Jean Shinoda Bolen. Visa-se, por fim, demonstrar como o núcleo familiar influencia na ordem social.

Palavras-chave: Familia. Direito. Príncipio. Função. Social.

ABSTRACT: This article seeks explanation about the social function principle of the Family and its significance to the Country's development. Focus on relevance of the Country's actions to accomplish the natural duties and obligations of families relations and on preservation of human dignity. On this coursework we apply an impartial analysis of the family Community as first social contact of children and teenager. The analysis will be made by logical reasoning, using qualitative approach, and presented on a bibliographic review form with a brief historical-social analysis, Consulting national and international laws, as well as academics courseworks that highlights the preservation of the family social function. Also focusing on Human Rights, children and teenagers rights, moreover the necessity of family social function to its implementations, using as comparative basis the United States and Japan. Bringing as conceptual basis, mostly the law doctrinators Lucas Calderón and Dimas Messias de Carvalho. Using also the knowledges and fundamentals of the studious Jean Shinoda Bolen. Aiming, finally, to demonstrate how the family core affects the social order.

Keyword: Family. Rights. Principle. Social. Function.

'Concluinte do Curso de Graduação de Direito, gabylauzid2@hotmail.com

${ }^{2}$ graduado em Direito pela Univerdade Federal do Pará (1982), procurador de Justiça do Ministério Público do Estado do Pará, professor Emérito da Faculdade Integrada Brasil Amazônia, Especialista e Mestre em Direito do Estado. 


\section{INTRODUÇÃO}

O presente projeto de pesquisa tem por objetivo abordar sobre a importância da familia para o desenvolvimento do Estado. Tratar-se-á do Princípio da Função Social da Família, pretedendo-se pôr em destaque os efeitos sociais provenientes do convívio familiar.

Dessa forma, visa-se discorrer a respeito da influencia do plano Micro (comunidade familiar) no Macro (sociedade). Na oportunidade, tratar-se-á das mazelas sociais decorrentes da inserção do indivíduo adulto no corpo social, sendo ele um cidadão fruto de uma família disfuncional.

Em breve investigação das origens do Direito de Família no contexto brasileiro (ALVES, 2020. p. 197), tem-se que o Código inaugural da Pátria foram as Ordenações Filipinas. Dada a descoberta do Brasil, bem como a aquisição do título de colônia portuguesa, o ordenamento jurídico português passou a vigorar em solo brasileiro, o que sucedeu na constância das Ordenações Filipinas até a criação do Código Civil de ı1ı́6 - Ainda que as mesmas tenham sido revogadas em Portugal no ano de 1867.

Ao período em que foram promulgadas, isto é, ao final do século $\mathrm{XV}$, a Europa passava pelo período denominado Baixa Idade Média, por consequência, o cerne dos dispositivos legais eram pautados em direito canônico com fortes traços ideológicos, políticos e sociais intrínsecos ao feudalismo (MIATELLO, 2013. p. I8I).

Em paralelo, no âmbito familiar observava-se a influência de cunho hierárquico e autoritário, cujo poder se concentrava na figura do Senhor, representado nos núcleos familiares pela figura masculina.

O Código Civil de 1916, obra memorável ao seu tempo, não acompanhou a rápida evolução e modificação dos costumes, especialmente na estrutura familiar patriarcal do século passado, na qual prevalecia a autoridade do homem, enquanto provedor, marido e pai. A vontade do pai era fundamental e determinante, sendo imposta aos dependentes como lei (CARVALHO, 2019. p. 4I).

Ainda que admitido e reformulado recentemente, a Função Social da Família constituía uma noção preexistente ao tempo das Ordenações Filipinas. Nota-se que a atuação esperada deste instituto social era voltada para a proteção patrimonial e ao anteparo sacramental do matrimônio objetivando unicamente a procriação. 
Conclui-se, portanto, que sua função social era zelar pela imagem pública do indivíduo (ainda que custasse a felicidade de seus membros) e garantir a perpetuação do patrimônio no nome da família (preservando o status social atribuído ao sobrenome). Tais características persistiram no Código Civil de 1916, evidenciadas em sua redação conservadora, positivista e patrimonialista, conforme estudado no curso de Direito Civil.

Em leitura ao conteúdo das Ordenações Filipinas (ALMEIRA, 202I), observa-se a defasada legislação que vigorou no Brasil durante extenso período. Conflitante com a dialética social, preconceitos e tabus cruzaram a barreira do tempo, remanescendo até os dias de hoje, dissimulados como traços culturais: educação punitiva; a subjugação da mulher; homofobia; intolerância religiosa - todas formas de violência antes amparadas pelo Direito e passadas pelas gerações na forma de juízo moral.

A Constituição Federal de 1988 apresentou ao ordenamento jurídico brasileiro uma gama de princípios capazes de reformular o conceito de função social da família. A partir da liberdade de interpretações doutrinárias em favor do princípio da Dignidade da Pessoa Humana, depreenderam-se elementos como: liberdade de planejamento familiar, pluralismo de entidades familiares, igualdade dos cônjuges, melhor interesse do menor, solidariedade familiar e demais orientações que atualmente compõem o rol de Princípios norteadores do Direito das Famílias?3.

Dessa forma, a compreensão da família torna-se um fato cultural, em razão da construção da afetividade na convivência, sem interesses materiais, envolta em um ambiente de solidariedade e responsabilidade, privilegiando a realização pessoal e o desenvolvimento de cada membro que a integra. A família verdadeira é a afetiva, antes de ser jurídica (ROSA, 2013).

A partir dos avanços acadêmicos no que tangem a formação da sociedade e do indivíduo, verificou-se a necessidade do diálogo entre o Estado e a Família. O Estado se manifesta na família, nesse contexto, para proteger prioritariamente os sujeitos familiares vulneráveis, como as crianças e os adolescentes, os idosos e os portadores de deficiências mentais (TEIXEIRA, 20I0).

\footnotetext{
3 Diante da repersonalização das relações famíliares, Doutrinadores como Dimas Messias de Carvalho, Maria Berenice Dias, Cristiano Chaves de Farias e Rolf Madaleno têm dado preferências ao uso do termo "Direito das Famílias".
} 
A Constituição de 1988 absorveu transformações da família, acolheu a nova ordem de valores e privilegiou a Dignidade da Pessoa Humana, reconhecendo a entidade familiar plural com outras formas de constituição além do casamento, vedando a discriminação dos filhos concebidos dentro ou fora do casamento e consagrou o princípio da igualdade entre homens e mulheres (CARVALHO, 2019. p.122).

Desta visão, originou-se o atual Código Civil, que se encontra em vigor desde o ano de 2003. Nele, o Direito das Famílias estabelece maior amparo à valorização dos aspectos existenciais do indivíduo, prezando pela personalidade e pela solidariedade entre seus membros. Além disso, busca satisfazer a atual Função Social da família, onde o Direito zela pela solidariedade entre seus membros, a preservação da dignidade individual de cada um deles, objetivando a futura inserção social de indivíduos íntegros na sociedade, conforme será explanado neste trabalho acadêmico.

Diante do exposto, este estudo encontra sua justificativa no interesse do Estado na efetivação do Princípio da Função Social da Família, enquanto elemento essencial para concretização da dignidade da pessoa humana. Dessa forma, analisar-se-á a família como fonte primária de comportamento do indivíduo em sociedade.

\section{SINTESE DA ORIGEM DA FAMÍLIA}

O filósofo e jurista, Clóvis Beviláqua ${ }^{4}$ entende a família como uma criação natural, mas reconhece que esta recebe influências sociais que irão moldá-la:

A esses fatores biológicos e psíquicos se vêem aliar outros de natureza sociológica. [...] Mas a disciplina social, pouco a pouco, intervém, pela religião, pelos costumes, pelo direito, e a sociedade doméstica se vai, proporcionalmente, afeiçoando por moldes mais seguros, mais definíveis e mais resistentes. Somente depois dessa elaboração é que alguns escritores querem que exista a família, que assim seria um produto seródio da vida social. Penso, ao contrário, que não passa ela de uma criação natural, que a sociedade amolda e aperfeiçoa. Sabe-se, no entanto, que a família não é resultado apenas de um fato natural, recebendo influências culturais dos povos, sendo moldada de acordo com aspectos religiosos, culturais e sociais (BEVILAQUA, i976. n.p). (grifo nosso).

Para o sociólogo Ferdinand Tönnies5, o conceito de Comunidade é pautado na partilha de características comuns entre os indivíduos de um grupo, um exemplo seria o

\footnotetext{
${ }^{4}$ Clóvis Beviláqua, jurísta e filósofo brasileiro, foi um dos responsáveis pela elaboração do Código Civil de I916.

5 Ferdinand Tonnies foi um sociólogo, economista e filósofo alemão. Fez grande contribuição acadêmica a partir de seus estudos sobre grupos sociais e comunidades.
} 
parentesco. Outrossim, a Sociedade é baseada em critérios e constituições que podem ser comuns a várias comunidades.

Frente a estes pensamentos, identificamos que a estrutura do vínculo familiar é resultado da associação de pessoas, conectadas entre si por laços biológicos e sociais.

Família é, portanto, uma Comunidade que sofre efeitos da Sociedade a qual está inserida, tais efeitos dependem do contexto histórico, geográfico e jurídico os quais, por consequência, influenciarão na comunidade familiar que, por sua vez, será um dos eixos da edificação social.

\section{${ }_{3}$ O PRINCÍPIO JURÍDICO COMO FONTE DE DIREITO}

Os princípios jurídicos são o sustento da lei. Para o doutrinador Maurício Godinho Delgado $^{6}$, o princípio jurídico é, de maneira geral, a noção de proposições fundamentais que se formam na consciência das pessoas e grupos sociais a partir da certa realidade, e que, após formadas, direcionam-se à compreensão, reprodução ou recriação da realidade (DELGADO, 20II. p. I8o).

São fontes primárias e formais de Direito, que correspondem ao tratamento social atribuido a determinado valor, dessa forma, dependem da época a qual estão inseridos. No entender de Miguel Reale7 os princípios são verdades fundantes de um sistema de conhecimento, como tais admitidas, por serem evidentes ou por terem sido comprovadas, mas também por motivos de ordem prática de caráter operacional, isto é, como pressupostos exigidos pelas necessidades da pesquisa e da práxis (REALE, I99I. p. 299).

Em complemento, para Celso Antônio Bandeira de Mello ${ }^{8}$ a definição de princípio se dá a partir do pensamento:

[...] é, por definição, mandamento nuclear de um sistema, verdadeiro alicerce dele, disposição fundamental que se irradia sobre diferentes normas compondo-lhes o espírito e servindo de critério para sua exata compreensão e inteligência, exatamente por definir a lógica e a racionalização do sistema normativo, no que lhe confere a tônica e lhe dá sentido harmônico. É o conhecimento dos princípios que preside a intelecção das diferentes partes componentes do todo unitário que há por nome sistema jurídico positivo [...] (Ibidem, Gelgado. 20II. p. 180). (grifo nosso.)

\footnotetext{
${ }^{6}$ Jurísta brasileiro e Ministro do Tribunal Superior do Trabalho.

7 Secretário da Justiça do Estado de São Paulo, professor e doutrinador de Filosofia Geral do Direito.

${ }^{8}$ Celso Antônio Bandeira de Mello é um jurísta e doutrinador brasileiro, considerado um dos maiores administrativistas do Brasil.
} 
A partir da compreensão dos excertos susoditos conclui-se que, os princípios pertencem ao rol de noções elementares utilizadas para alinharem a ideologia jurídica a qual pretende-se seguir. Nesse sentido, foi incorporado no corpo da LINDB - Lei de Introdução das Normas Brasileiras, a qualidade subsidiária dos Princípios enquanto instrumento jurídico:

Art. 4- Quando a lei for omissa, o juiz decidirá o caso de acordo com a analogia, os costumes e os princípios gerais de direito. (grifo nosso) ${ }^{9}$.

Ainda, a autoridade dos princípios foi reconhecida na presente redação do atual Código de Processo Civil. Vejamos:

Art. 80 Ao aplicar o ordenamento jurídico, o juiz atenderá aos fins sociais e às exigências do bem comum, resguardando e promovendo a dignidade da pessoa humana e observando a proporcionalidade, a razoabilidade, a legalidade, a publicidade e a eficiência. (BRASIL, 2015). (grifo nosso)

Isso posto, observa-se o reconhecimento do legislador no que concerne à legitimidade dos princípios enquanto fonte de Direito capaz de espelhar os ideais usados para alcançar a justiça. Outrossim, Celso Antônio Bandeira de Mello conclui:

Violar um princípio é muito mais grave que transgredir uma norma qualquer. A desatenção ao princípio implica ofensa não apenas a um específico mandamento obrigatório, mas a todo o sistema de comandos. É a mais grave forma de ilegalidade ou de inconstitucionalidade (MELLO, 200o. p. 747). (grifo nosso).

Em última análise ao tópico, é inegável a importancia dos princípios como fonte de Direito em virtude de sua função basilar, a qual sustenta a essência da norma jurídica e que traça o caminho o qual deve-se seguir para atingir o resultado que se objetiva.

\section{I O PRINCÍPIO DA FUNÇÃO SOCIAL DA FAMÍLIA}

Como aprendido no curso de Direito, o princípio da Função Social da Família é um dos pilares do atual Direito das Famílias.

O instituto familiar é inconstante e mutável, uma vez que seus componentes (humanos) também o são. No entanto, a partir dos estudos relacionados à função social da família e, analisando as pespectivas de Doutrinadores como Dimas Messias de Carvalhoro,

\footnotetext{
ro Assim entende Dimas Messias de Carvalho: "O moderno direito de família agasalha, ainda, as diversas formas de família constituídas pela convivência e afeto entre seus membros, se importar o vínculo biológico e o sexo. A afetividade é atualmente o elemento agregador da entidade familiar, na busca sempre de uma família eudemonista que se realiza na felicidade e na proteção de cada um dos membros que a integra".
} 
Rodrigo da Cunha Pereira ${ }^{\mathrm{II}}$ e Maria Berenice Dias ${ }^{\mathrm{I2}}$, compreende-se que a atual função social da família é, em caráter básilar, a felicidade, visto tratar-se de elemento corrente e de suma importancia em suas teses.

Todavia, em apreciação aos conhecimentos Doutrinários, percebe-se não se tratar de simples felicidade, mas sim da Justa Felicidade, uma vez que deve ser inserida nos moldes do Direito. Em alusão ao filósofo inglês Herbert Spenceri33, a Justa Felicidade seria àquela que teria fim onde a do próximo começa.

O Princípio da função social da família tem por propósito a tutela do Estado posto o dever da família em propiciar um ambiente digno, estável e de desenvolvimento saudável para todos os seus membros, pois representa o espaço onde as células da sociedade aperfeiçoarão sua individualidade, comportamentos e valores próprios.

Para Cristiano Chaves Farias ${ }^{14}$ a unidade familiar é dotada de particularidades que devem ser apreciadas a partir de suas singularidades:

Dessa maneira, a família deixa de ser um fim em si mesmo e passa a ser um meio para a busca da felicidade, da dignidade da pessoa humana. As relações familiares devem ser analisadas dentro de um contexto social, levando-se em consideração as peculiaridades de cada caso. (FARIAS, 2017. p. n.p). (grifo nosso).

Entende-se, portanto, a imprescindibilidade de sua aplicação na interpretação das normas de Direito, pois divide-se em aspectos jurídicos e morais os quais regem a sociedade - fulcro do desenvolvimento social.

\section{A FAMÍlIA COMO FONTE PRIMÁRIA DE COMPORTAMENTO}

Diante da proposta em análise, convém a afirmativa: a família é fonte primária de comportamento em sociedade. Introduziremos este tópico com auxílio do seguinte fragmento kafkaniano:

E como eras meu verdadeiro educador, tudo isso influiu sobre minha vida geral. [...] Ou melhor, todas as tuas normas de educação foram acertadas; não esqueci

\footnotetext{
II Depreende-se a felicidade como elemento fundamental a partir de sua afirmativa "Não existe um modelo a ser seguido, mas uma felicidade a ser buscada".

${ }_{12}$ Assim postula Maria Berenice Dias: "Assim, mesmo não expresso explicitamente na Constituição Federal, o direito à felicidade existe e precisa ser assegurado a todos. Não só pelo Estado, mas por cada um, que além de buscar a própria felicidade, precisa tomar consciência que se trata de direito fundamental do cidadão, de todos eles".

${ }^{13}$ Herbert Spencer, célebre representante do Liberalismo Clássico. Foi filósofo, biólogo e antropólogo, também autor da frase: "A liberdade de cada um termina onde começa a liberdade do outro".

${ }^{14}$ Mestre em Família na Sociedade Contemporânea pela Universidade Católica do Salvador - UCSal.
} 
nenhum pormenor; tal como sou, represento (excluindo naturalmente os fundamentos e a influencia da vida) a consequência de tua educação e minha obediencia." (KAFKA, 2004). (grifo nosso).

A partir da passagem em destaque, observamos a influencia da conduta dos pais ao longo da vida de seus filhos. Segundo o jurista Washington de Barros Monteiro ${ }^{15}$, é na unidade familiar onde originam-se e desenvolvem-se hábitos, inclinações e sentimento que decidirão um dia a sorte do indivíduo (MONTEIRO, 2004). Os parentes e responsáveis compartilham seus conhecimentos de vida ao longo de toda formação cognitiva da célula que virá a ser um componente na esfera de convívio coletivo.

Experimentalmente, ao observamos com atenção, a inocência infantil atribui aos tutores certa presunção de veracidade. A partir desta presunção surge a matéria que alimenta o imaginário lúdico, mas que também dá impulso aos (pré)conceitos os quais foram inseridos de forma estrutural em nossa sociedade.

Portanto, família é onde temos o primeiro contato com (pré)conceitos, comportamentos e valores que formam a subjetividade que particulariza cada ser humano.

A psicologia, por sua vez, enxerga a subjetividade como a síntese distintiva e individual que cada um de nós vai construindo conforme vamos nos desenvolvendo e vivenciando as experiências da vida social e cultural (BOCK, 2005).É a subjetividade que faz com que dois indivíduos sob as mesmas contigências operem de formas distintas.

A partir deste entendimento, compreende-se que uma família disfuncional tem mais chances de gerar indivíduos disfuncionais:

\footnotetext{
Um genitor que não controla seu próprio "urso forte e feroz" fere com palavras destrutivas e/ou maltrata os filhos. Quer testemunhe isso dirigido a outro membro da família ou o sofra ela mesma, a criança fica assustada e é prejudicada por isso, tendo com frequência problemas para controlar seus próprios impulsos destrutivos. Viver numa família em que a raiva e o medo estão no ar e as pessoas se sentem inseguras reforça esses impulsos (BOLEN, 2020. p. 134). (grifo nosso).
}

Nesta pespectiva, a Doutora Jean Shinoda ${ }^{16}$ afirma que da família disfuncional "decorre a probabilidade de que a criança maltratada venha a ser um pai que maltrata". Em alusão ao fragmento introdutório deste tópico, o autor Franz Kafka acreditava que seu pai utilizava-se de tais métodos agressivos pela forma como foi educado em sua infância: "Tu

\footnotetext{
is Professor em Direito Civil da Faculdade Paulista de Direito, da Pontifícia Universidade Católica de São Paulo.

${ }^{16}$ Jean Shinoda Bolen, médica com doutorado, psiquiatra e analista junguiana estadunidense.
} 
somente podes tratar um menino do mesmo modo como foste tratado, com força, ruído e iracúndia $[\ldots] ”($ KAFKA, 2004).

Consciente de que a violência é dos principais problemas sociais brasileiros e que este fenômeno é complexo e multicausal, a família configura-se como um dos contextos em que pode determinar e manifestar esta violência (FIGUEIREDO, 202I).

Ainda, Shinoda complementa: "quando adulto, a criança fica suscetível ao esgotamento emocional, síndrome do pânico, depressão, compulsão alimentar, bem como dependência química e agressividade", fatores estes também exemplificados na obra da Kafka:

Contudo, anos depois sofri diante da imagem atormentadora do homem gigantesco, meu pai, a última instância, que podia, quase sem motivo, vir de noite tirar-me da cama, levar-me à varanda, e que portanto, até esse ponto eu nada significava para ele. Aquilo foi, então, um pequeno princípio, mas esta sensação de nulidade (sob outro ponto de vista, sem dúvida, uma sensação também nobre $e$ frutífera), que com frequencia me domina, foi em grande parte provocada pela tua influencia”. (Ibidem, KAFKA, 2004. p. 8I). (grifo nosso).

Ocorre que, em função disto, serão introduzidos na sociedade indivíduos cujo comportamento desviará da conduta normativa, impactando diretamente no Estado democrático de direito. Ciente disso, o Estado busca se manifestar das mais diversas formas no que tange à proteção da família, a exemplo o artigo 226 da Constituição Federal de 1988:

Art. 226. A família, base da sociedade, tem especial proteção do Estado.

$\S 7^{\circ}$ Fundado nos princípios da dignidade da pessoa humana e da paternidade responsável, o planejamento familiar é livre decisão do casal, competindo ao Estado propiciar recursos educacionais e científicos para o exercício desse direito, vedada qualquer forma coercitiva por parte de instituições oficiais ou privadas.

$\S 8$ o O Estado assegurará a assistência à família na pessoa de cada um dos que a integram, criando mecanismos para coibir a violência no âmbito de suas relações. (BRASIL, 1988). (grifo nosso).

O interesse do Estado na proteção da família é, fundamentalmente, garantir a ordem social. Para Francisco José Carvalho ${ }^{17}$, a função social do direito é o fim comum que a norma jurídica deve atender dentro de um ambiente que viabilize a paz social (CARVALHO, 202I). Por consequência, indivíduos mentalmente instáveis provenientes de famílias disfuncionais tendem a agir contra a ordem e a paz social. Vejamos:

A Folha de São Paulo de oI/o2/1992 publica em sua página 22 que o The New York
Times divulgou um estudo do Departamento de Justiça dos Estados Unidos sobre
a criminalidade, afirmando que esta pode ter sua origem na família. [...] mais da

${ }_{17}$ Mestre em Função Social do Direito - FADISP. Pós-graduação em Direito Civil - UniFMU. Pós-graduação em Direito Ambiental - USP. 
metade de todos os delinqüentes juvenis presos nos reformatórios estaduais e mais de um terço dos criminosos adultos em prisões estaduais têm algum membro próximo da família que também já esteve encarcerado. Terrie Moffitt, professora de Psicologia da Universidade de Wiscosin, declara que as estatísticas contradizem a tese de que os jovens se tornam delinqüientes por influência de amigos. Para ela, os jovens aprendem a ser criminosos com suas próprias famílias. (CERVENY, 200o). (grifo nosso).

Dessa forma, as disfunções (violência intrafamiliar) que ocorrem neste cenário além de romperem com o vínculo e os laços de solidariedade entre os membros, tem efeito direto sobre a tendência à prática de atos infracionais pelos adolescentes (FIGUEIREDO, 202I).

Ainda que influenciado pelas demais experiências sociais e culturais, é na família onde forma-se o mais íntimo traço da personalidade de um indivíduo, onde a subjetividade moldará suas ações. Embora imprevisíveis, as atitudes humanas podem e devem ser orientadas e corrigidas pelo Direito, motivo pelo qual o Estado preza pelas relações familiares.

\section{I A FUNÇÃO SOCIAL DA FAMÍLIA NO DIREITO COMPARADO}

Conforme visto no tópico anterior, a função social da família é componente essencial para a efetivação da Dignidade da Pessoa Humana, Princípio amparado pela Declaração Universal dos Direitos Humanos ${ }^{18}$ cuja matéria foi admitida por mais de 193 países signatários, segundo dados disponibilizados pelo site oficial das Nações Unidas (UNITED NATIONS, 2014).

Destarte, a família é um dos instrumentos fundamentais para a efetivação do papel dos direitos humanos (SMANIOTTO, 2020). Tendo em vista tal entendimento, e levando em consideração que grande parte da conduta social do individiuo é traçada na infância, surgiu o ânimo de salvaguardar os direitos das Crianças, levando em consideração os aspectos obrigacionais dos familiares para com o infante.

Dessa forma, faz-se necessário mencionar a responsabilidade do cidadão para como Estado. Sob os argumentos do sociólogo Rosseau, o homem nasce com uma dívida para com a Sociedade, sendo esta paga por meio da criação de suas crianças a fim de que se tornem

${ }^{18}$ Adotada e proclamada pela Assembleia Geral das Nações Unidas (resolução 217 A III) em Io de dezembro 1948 . 
cidadãos íntegros e que venham a acrescer, de forma positiva, ao corpo social. (ROSSEAU, 1973).

Diante disto, no preâmbulo da Convenção sobre os Direitos da Criança ${ }^{19}$, constam as seguintes considerações:

Convencidos de que a família, como grupo fundamental da sociedade e ambiente natural para o crescimento e o bem-estar de todos os seus membros e, em particular, das crianças, deve receber a proteção e a assistência necessárias para poder assumir plenamente suas responsabilidades dentro da comunidade; reconhecendo que a criança, para o pleno e harmonioso desenvolvimento de sua personalidade, deve crescer no seio da família, em um ambiente de felicidade, amor e compreensão;

Considerando que a criança deve estar plenamente preparada para uma vida independente na sociedade e deve ser educada de acordo com os ideais proclamados na Carta das Nações Unidas, especialmente com espírito de paz, dignidade, tolerância, liberdade, igualdade e solidariedade; (RENAUT, 2002). (grifo nosso).

Outrossim, além da tutela de direitos subjetivos do infante, a Convenção oferece assistencia no ambito fático: no combate de tráfico de crianças, prostituição e pornografia infantil, além do envolvimento de crianças em conflitos armados.

Pautada nos princípios da Participação, Sobrevivencia e Desenvolvimento, Interesse Superior da Criança e Não Discriminação, a covenção é vista como uma das mais eficientes formas de concretização dos Direitos Humanos, no entanto, diante das variedades multiculturais, observam-se complicações em sua efetivação, bem como as consequências sociais decorrentes destas. Adiante, sintetizaremos breves polêmicas concernentes à sociocultura e ao direito comparado.

\subsection{Estados Unidos}

A tensão intrínseca ao texto da Convenção tem sua complexidade ampliada perante o caráter de força de lei que passa a ter no país que opta por ratificá-la, o que pode explicar o grande número de discussões que suscitou em alguns países ao ser adotada, bem como as dificuldades em sua implementação ${ }^{20}$.

Os Estados Unidos, simpatizante do avanço da Democracia e auto-declarado pelo qualificativo "Estado Livre”, é, atualmente, o único país não signatário da Convenção sobre

19 “É o instrumento de direitos humanos mais aceito na história universal. Foi ratificado por 196 países. Somente os Estados Unidos não ratificaram a Convenção. O Brasil ratificou a Convenção sobre os Direitos da Criança em 24 de setembro de 1990" (Convenção sobre os Direitos da Criança. Brasil, i99o. Disponível em: https://www.unicef.org/brazil/convencao-sobre-os-direitos-da-crianca. Acesso em: 04 de outubro de 202I). 
os Direitos da Criança, conforme notíciado no site oficial da Orgnização das Nações Unidas (ONU, 2015).

Ocorre que, a doutrina majoritária do País - representada neste trabalho pelo argumento de Michael P Farris ${ }^{21}$ - acredita ser um afrontoso avanço do Estado no controle parental e na criação privativa da infancia americana:

A principal ameaça representada pela CRC (Convention on the Rights of the Child) é a negação do autogoverno americano de acordo com nossos processos constitucionais. Nosso sistema constitucional atribui exclusiva autoridade para a criação de leis e policia nos problemas infanto-familiares aos governos dos Estados.

Diante da ratificação, esta nação estaria fazendo uma promessa imperiosa de ambito internacional que nos obrigaria aos parametros legais criados pela U.N. CRC. As crianças e as famílias americanas estão melhor amparadas pelo sistema democrático constitcuional do que pela lei internacional ${ }^{22}$. (tradução nossa).

Por consequência, observam-se diversas questões fundamentais embaçadas pelos obstáculos impostos à efetividade da Convenção sobre os Direitos da Criança.

O Washinton Post destaca que o temor da ratificação advém da possibilidade das crianças escolherem sua própria religião; da existencia do direito exigível ao lazer; do aumento de gastos na proteção e bem-estar da infância nacional; e, sobretudo, o surgimento do direito da criança ser "ouvida", uma vez que estimularia a revisão de qualquer decisão feita pela família e que desagrade a criança (THE WASHINGTON POST, 2014).

Diante da não ratificação, sob o argumento de que as políticas internas satisfazem as necessidades sociais, nos deparamos com a não uniformização do direito das crianças nos Estados componentes da república federativa estadunidense. Em consequencia disso, o amparo a estes direitos se dá por diferentes formas a depender da localidade, resultando na limitação e até exclusão social da criança - A qual torna-se mera extensão de seus responsáveis. ${ }^{23}$

\footnotetext{
${ }^{21}$ Militante na área do Direito Constitucional estadunidense e presidente do ParentalRights.org.

${ }_{22}$ "The chief threat posed by the CRC is the denial of American self-government in accord with our constitutional processes. Our constitutional system gives the exclusive authority for the creation of law and policy on issues about families and children to state governments. Upon ratification, this nation would be making a binding promise in international law that we would obey the legal standards created by the U.N. CRC. American children and families are better served by constitutional democracy than international law". The Washington Post, 2014. Disponivel em: https://www.washingtonpost.com/blogs/post-partisan/wp/20I4/ri/2I/why-wont-the-u-s-ratify-the-u-n-schild-rights-treaty. Acesso em: 04 de outubro de 2021.

${ }_{23} \mathrm{Tal}$ realidade materializa-se principalmente nos castigos corporais, aplicados mesmo nas escolas. No ano 2007, o Departamento de Educação dos Estados Unidos reportou que mais de 200,00o estudantes teriam sofrido castigos corporais. Disponível em: https://www.humanium.org/en/united-states-of-america/. Acesso em: 27 de outubro de 202r.
} 
Em face disso, o maior impacto internacional, fruto da renúncia dos Estados Unidos à Convenção sobre os Direitos da Criança, é, sem dúvida, a vulnerabilidade das crianças, principalmente das migrantes e refugiadas, uma vez que a separação das famílias é uma realidade recorrente nos Estados Unidos:

Infelizmente, a detenção de crianças migrantes nos Estados Unidos é um exemplo vergonhoso da necessidade de incorporar o princípio do melhor interesse da criança nas decisões políticas dos EUA. Famílias são separadas. As crianças são rotineira e arbitrariamente detidas, muitas vezes em instalações que não são apropriadas para crianças.

Eles não estão suficientemente protegidos contra agressões e abusos sexuais, em violação à lei dos EUA, conforme constatou um relatório recente da Comissão de Direitos Civis dos EUA.

E as crianças passam longos períodos de tempo em condições que são prejudiciais à sua saúde física e mental. Um amplo grupo de americanos, incluindo muitos grupos religiosos, pediu ao governo Obama que acabe com a prática prejudicial de detenção de familiares (HUFFPOST, 2016).

Ainda, considerando o panorama relativamente próspero e desenvolvido, observa-se que a sociedade norte-americana é berço dos mais ultrajantes crimes hediondos ${ }^{24} \operatorname{cometidos~}$ por seus jovens integrantes.

Para ilustrar o trágico cenário, basta uma breve análise referente aos episódios de extermínio das últimas duas décadas, vejamos: Columbine High School, Colorado (EUA), 1999; Virginia Tech University, Virginia (EUA), 2007; Sandy Hook Elementary School, Connecticut (EUA) em 2012; Santa Fe High School, Texas (EUA), 2018; Marjory Stoneman Douglas High School, Flórida (EUA), 2018; YES Prep Southwest School, Texas (USA), 2021; Newton Elementary School, Mississippi (EUA), 2021. (FOLHA DE SÃO PAULO, 202I).

Dessa forma, observa-se a complexidade do entendimento da Função Social da Família e sua aplicação no Direito Comparado, visto que sua efetividade varia conforme a compreensão cultural de qual seria finalidade do núcleo famíliar, bem como a limitação de poder dos pais/responsáveis.

\subsubsection{Japão}

A partir do senso comum, o Japão é reconhecido mundialmente pelo juízo de comunidade desenvolvido por sua sociedade, representado principalmente pela ligeira reestruturação pós-catastrofes (sejam estas provenientes de guerras ou natureza), ou por seu

${ }^{24} \mathrm{Na}$ legislação brasileira, no rol dos crimes hediondos integram os crimes de homicídio, quando praticado em atividade típica de grupo de extermínio, homicídio qualificado. 
célere desenvolvimento social e tecnológico, o Japão sofre com divesas disfunções sociais cujo fulcro encontra-se na família.

Atualmente, a sociedade japonesa sofre com problemas estruturais decorrentes do patriarcado ${ }^{25}$, representado pelos altos índices de violência doméstica, pedofilia e suicídio, como rapidamente trataremos adiante:

O jornal The Japan Times trouxe à exame os atualizados índices de violência intrafamiliar:

\begin{abstract}
Os casos de violência doméstica no Japão atingiram um recorde de mais de 130.000 no ano fiscal de 2020 , com as pessoas mais estressadas e preocupadas com a vida, já que a pandemia do coronavírus as força a passar mais tempo em casa, de acordo com uma pesquisa do governo divulgada na terça-feira.

O número total de casos foi de 132.355 no período de abril a novembro, quatro meses antes do final do ano fiscal em 31 de março, superando o nível fiscal de $2019 \mathrm{em}$ 13.000 .

Houve mais de 15.000 casos por mês entre abril e novembro, com números particularmente altos em maio e junho, mostrou a pesquisa do Cabinet Office. ${ }^{26}$.
\end{abstract}

Em manifestação a respeito da pesquisa do jornal, Seiko Hashimoto, Ministra da igualdade de gênero, assim pronunciou-se em entrevista coletiva: "Precisamos acompanhar de perto a situação e fortalecer as medidas depois que o governo declarou um segundo estado de emergência em relação ao coronavírus".

Não obstante, o Estado japonês se vê em um embate cultural ${ }^{27}$ entre a tolerância à pedofilia e os Direitos da Criança. Sabe-se que a idade do consentimento para relações sexuais no Japão é de $13 \operatorname{anos}^{28}$ (THE JAPAN TIMES, 202I), motivo pelo qual a exploração sexual de jovens dessa faixa etária é admitida.

\footnotetext{
${ }^{25}$ Historicamente, a família japonesa é influenciada pelos ideais da "Piedade Filial" que é definida pela virtude de respeito aos pais e antepassados. Tradicionamente, o poder familiar concentra-se na autoridade patriarcal, que exerce a responsabilidade por todos os membros da família. IES, 2021. Disponível em: https://culturalatlas.sbs.com.au/japanese-culture/japanese-culture-family. Acesso em: 04 de outubro de 202I. ${ }^{26}$ Domestic violence cases in Japan hit a record high of over 130,000 in fiscal 2020, with people more stressed and worried about life as the coronavirus pandemic forces them to spend more time at home, according to a government survey released Tuesday. The total number of cases stood at 132,355 in the period from April to November, four months before the fiscal year ends on March 31, surpassing the fiscal 2019 level by 13,00o. There were over 15,00o cases per month between April and November, with numbers particularly high in May and June, the Cabinet Office survey showed. The Japan Times, 2021. Disponível em: (https://www.japantimes.co.jp/news/2021/or/13/national/domestic-violence-casesrecord-high/) Acesso em: 04 de outubro de 2021.

27 Trata-se de um embate cultural pois contrasta com a comum prática do Enjo Kosai, onde homens mais velhos contratam "garotas colegiais" para serviços de acompanhante. Em algumas regiões do Japão, tal prática é considerada como um rito de passagem para a vida adulta.

${ }^{28}$ Ainda que a maioridade civil do Japão seja alcançada aos 20 anos de idade 年齢二十歳をもって、成年と する。English: Article 4 The age of majority is 20 years of age. Tradução nossa: A idade para maioridade é de anos de idade. Disponível em:
} 
Ademais, a sexualização da criança e do adolescente é cultuada na mídia japonesa, criando raízes na atualidade sob égide da cultura pop nos gêneros Lolicon e Shotacon ${ }^{29}$, previamente debatida pela Organização das Nações Unidas:

O Comitê está profundamente preocupado com a grande quantidade de material on-line e off-line, incluindo desenhos e representações virtuais, representando crianças inexistentes ou pessoas que parecem ser crianças envolvidas em conduta sexualmente explícita e sobre o sério efeito que esse material pode ter sobre o direito à dignidade e proteção das crianças. O Comitê incentiva os Estados partes a incluir em suas disposições legais as representações materiais de abuso sexual infantil (pornografia infantil) de crianças inexistentes ou de pessoas que parecem ser crianças, especialmente quando tais representações são usadas como parte de um processo para explorar sexualmente crianças. (OHCHR, 1996-202I). (tradução e grifo nosso).

Nesse interím, a Organização das Nações Unidas propôs novas diretrizes a serem seguidas no que tange o protocolo facultativo referente à venda de crianças, prostituição e pornografia infantis para convenção dos direitos das crianças. O parágrafo 62 diz:

O Comitê apela para que Estados Participantes proíbam, por lei, todas as formas de materiais que contêm abuso sexual infantil. O Comitê nota que há um aumento na circulação desses materiais e recomenda fortemente aos Estados signatários a garantir que seus Códigos Criminais cobrem todas as formas, inclusive quanto os atos citados no artigo 3.I(c) são cometidos online e também quando tais materiais incluem representações de crianças não-existentes. (OHCHR, 1996-2021).

A posição do governo japonês, em contrapartida, foi de rejeição da matéria proposta pela ONU, alegando que tal proposta seria afronta ao direito de liberdade de expressão. Vejamos o pronunciamento do Ministério das Relações Exteriores do Japão:

http://www.japaneselawtranslation.go.jp/law/detail/? $\mathrm{ft}=2 \& \mathrm{re}=02 \& \mathrm{dn}=\mathrm{I} \& \mathrm{yo}=\mathrm{civil}+\mathrm{code} \& \mathrm{x}=\mathrm{I} 4 \& \mathrm{y}=\mathrm{I} 2 \& \mathrm{ia}=03$ $\& \mathrm{ja}=04 \& \mathrm{ph}=\& \mathrm{ky}=\&$ page $=3$ Acesso em: 19 de novembro de 2021.). A legislação civil japonesa é silente quanto à idade para o consentimento, sendo esta estipulada por meio da tradição, analogia ao seu código penal e por meio da jurisprudência. (Original: 第百七十七条 十三歳以上の者に対し、暴行又は脅迫を用いて性交、 肛門性交又は口腔性交（以下「性交等」という。）をした者は、強制性交等の罪とし、五年以上の有 期懲役に処する。十三歳未満の者に対し、性交等をした者も、同様とする。English: Article I77 A person who, through assault or intimidation forcibly engages in vaginal intercourse, anal intercourse or oral intercourse (hereinafter referred to as "sexual intercourse") with another person of not less than thirteen years of age is guilty of the crime of forcible sexual intercourse, and is punished by imprisonment for a definite term of not less than 5 years. The same applies to a person who engages in sexual intercourse against another person under thirteen years of age. Tradução nossa: Uma pessoa que, por meio de agressão ou intimidação, praticar relações sexuais vaginais, anais ou orais (doravante denominadas "relações sexuais") com outra pessoa de menos de treze anos de idade é culpada do crime de relação sexual forçada, e é punido com pena de prisão definitiva não inferior a 5 anos. $O$ mesmo se aplica a uma pessoa que mantém relações sexuais com outra pessoa com menos de treze anos de idade. Disponível em: http://www.japaneselawtranslation.go.jp/law/detail/?ft $=3 \& \mathrm{re}=02 \& \mathrm{dn}=\mathrm{I} \& \mathrm{ia}=03 \& \mathrm{ja}=04 \& \mathrm{ct} \_\mathrm{x}=98 \& \mathrm{ct} \_\mathrm{y}=2 \mathrm{o} \&$ $\mathrm{bu}=\mathrm{I} 6 \& \mathrm{ky}=$ \&page $=\mathrm{I3}$. Acesso em: 19 de novembro de 2021.)

${ }^{29}$ Enquanto Lolicon trata de garotas entre 9 à 14 anos de idades, Shotacon trata de garotos. Ambos são generos comuns à animês (desenhos animados) e mangás (revistas em quadrinhos). 
É decepcionante que essas diretrizes tenham sido divulgadas sem que o Comitê tenha discutido o suficiente entre os países, inclusive nosso país, que são afetados pelo protocolo opcional [...] $\underline{O}$ Japão acredita que a restrição à liberdade de expressão deve ser reduzida ao mínimo e que deve ser dada uma consideração muito cuidadosa ao escopo da pornografia infantil. (OHCHR, 1996-2021).

Dessa forma, sabendo que o aprendizado começa com o nascimento (ROUSSEAU, 1973), e tendo em mente que a criança representa o mais íntimo traço de formação da sociedade, e levando em consideração que os relacionamentos amorosos entre crianças e adultos envolvem uma relação mais de poder do que de afeto (LOURO, 1997), é importante refletir nas consequencias psicológicas e fatores sociais que tais condutas são capazes de gerar.

Nesta pespectiva, adentramos a delicada matéria do Suicídio. A mídia perpetuou a ideia de que o suicídio japonês é meramente ritualístico - visão parcialmente defasada. Em virtude das questões acima citadas, insta esclarecer que neste tópico trataremos do suicídio enquanto consequencia da disfunção psíquica do invidíduo (MOTOHASHI, ET AL, 2003).

Após análises, observou-se que o suicídio é a principal causa de morte na juventude e na terceira idade japonesa (BBC NEWS, 2015). Se na sociedade norte-americana os problemas sociais originados no plano familiar surgem na forma de violência social impulsiva e destrutiva, na realidade japonesa tem-se por resultado o atentado à própria vida como válvula de escape.

A rigidez na educação da infância japonesa é notória, conforme exaltado na mídia ${ }^{30}$. Assim sendo, percebe-se o complexo composto-social resultante da associação de produtividade tóxica/síndrome de impostor ${ }^{31}$, disseminado de forma cultural nas relações intrafamiliares japonesas. A psicóloga Agda Mattoso explica:

A questão a ser destacada é que ao viver de modo automatizado, priorizando o desempenho nas diversas áreas da vida, entra-se num padrão cíclico de pensar as relações humanas só pela ótica da produção, da utilidade e do sucesso. Ou seja, se não estou produzindo algo de útil, não me sinto bem. É como se tivesse algo errado em não ser produtivo o tempo todo do viver (SANTOS, MATTOSO, 2021). (grifo nosso).

30 Escolas Pelo Mundo. Notícias: Transformando.com.vc, is de julho de 2021. Disponível em: https://transformando.com.vc/escolas-pelo-mundo-conheca-como-e-a-educacao-no-japao/. Acesso em: 02 de dezembro de 2021.

${ }^{31}$ A Produtividade Tóxica e a Síndrome de Impostor, ainda que sem reconhecimento da Organização Mundial da Saúde, são disturbios já identificados pelos profissionais das áreas de saúde mental. São considerados vertentes de outras doenças psíquicas (já creditadas pela OMS) como ansiedade e depressão. Disponível em: https://www.paho.org/pt/topicos/depressao. Acesso em: 27 de outubro de 202I. 
Fatores como a exigência de produtividade, agregado à comparação estrutural (a qual atribui favoritismo àquele indivíduo de maior proveito familiar/social) possibilitam o surgimento de sequelas existenciais:

[...] querer ter filhos para manter o nome ou o negócio da família, para ser um atleta de sucesso, uma personalidade política ou qualquer coisa que o pai aspirou ser e agora pode viver por meio do filho. Quando isso é um padrão familiar, a criança para conservar a aprovação do pai, aprende a suprimir os próprios sentimentos e inclinações contrárias, crescendo sem se sentir amada pelo que é. (BOLEN, 2020. p. 87-88). (grifo nosso).

Compreende-se, portanto, que estas condições atentam contra a personalidade e a dignidade, dado que a partir da retração da subjetividade na infância, prosperam-se as chances da criança evoluir para um adulto apático, desesperançoso e insatisfeito consigo mesmo, confome explica Shinoda:

[...] as emoções não expressas de pesar, de vergonha, de horror, de dor e de medo são enterradas vivas na psique das vítimas. Quando são evocadas, mesmo que bem mais tarde, descobrimos que podem vir a inundar a pessoa de afetos. Se isso for demais para um ego frágil suportar, a loucura - a perda da realidade - pode se manifestar. (Ibidem, BOLEN, 2020, p 95). (grifo nosso).

Como mencionado anteriormente (item 4), surge a probabilidade de que a criança maltratada venha a ser um pai que maltrata, ou como posto em questão, venha a ser um cuidador negligente, o que gerará no idoso a pressão psicológica combustível para o desenvolvimento da conduta suicida. De mesma forma, a tensão se manifesta em consequencia da produtividade tóxica - a autodesvalorização e o estigma da inutilidade social - enraízam-se no emocional do indivíduo e elevam o potencial risco.

Sendo a função social da família primordial para satisfação dos direitos humanos, deveria o Estado contentar-se com o seu próprio desenvolvimento em função dos direitos fundamentais e integridade psicológica de seus integrantes? Isto é, o desenvolvimento japonês é inegável, de mesmo modo as disfunções sociofamiliares e seus impactos também o são.

Dessa forma, ratifica-se o incerto solo da função social da família na esfera internacional, uma vez que sua efetividade depende de adequação cultural e compreensão social.

No Brasil, a função social da família reestruturou-se sob a égide dos Direitos Humanos. A proteção e a assistencia à família não se destinam mais exclusivamente à 
instituição, como ocorria com a manutenção do casamento e a família legítima, mas na pessoa de cada um dos membros que a intera ( $\operatorname{art} 226, \S^{\circ} 8^{\circ}$, da CF), com a assistencia especial aos membros vulneráveis, como as crianças, os adolescentes e os idosos, além da proteção às mulheres contra a violência doméstica (CARVALHO, 2019).

O princípio da dignidade da pessoa humana importou na despatrimonialização e na repersonalização das relações de família, valorizando-se os aspectos existenciais e garantindo-se os direitos de personalidade de cada membro (CARVALHO, 2019).

A singela caminhada rumo a efetiva preservação dos componentes do núcleo familiar é resultado da evolução da moral coletiva, que impulsiona as correntes doutrinárias do Direito das Famílias.

Para Joshua Greene $e^{32}$, a moralidade é um conjunto de capacidades e tendências psicológicas que permitem que indivíduos egoístas aproveitem os benefícios da cooperação. Falando de forma coloquial, a moralidade diz respeito ao trabalho em equipe - a capacidade de agir em benefício de "nós” e não em benefício de “mim”. (BLUEVISION, 2018).

Regulamentada pela Lei Maior, o instituto da Família encontra na legislação brasileira diversas formas de consumar seu propósito - A Justa Felicidade e a Ordem Social. Percebe-se que a evolução moral, isto é, o atual pensamento de cooperação, viabilizou a estruturação de um ordenamento jurídico cujas políticas familiares destacam-se internacionalmente.

O Código Civil de 2002 incorporou no ordenamento jurídico brasileiro diversos meios de amparo ao instituto famíliar. Em análise, observamos a regulamentação matrimonial (ressaltando a facilidade da união e na dissolução - sendo alcançada também de forma extrajudicial), bem como o direito à alimentos, que garante a estabilidade estrutural para a criança.

Nesse panorama, os parentes, os cônjuges ou companheiros "podem pedir uns aos outros os alimentos de que necessitem para viver de modo compatível com a sua condição social, inclusive para atender às necessidades de sua educação" (REALE, 2003).

Em comentário ao artigo r.63o da atual legislação civil, Maria Helena Diniz explica sobre o novo entendimento do Poder exercido pelos entes familiares, sendo este:

32 Psicólogo, neurociêntista, e filósofo, Joshua Greener é também diretor do "Moral Cognition Lab" ("Laboratório de Cognição Moral”, em tradução livre) da Universidade Harvard. 
Um conjunto de direitos e obrigações, quanto à pessoa e bens do filho menor não emancipado, exercido em igualdade de condições por ambos os pais, para que possam desempenhar os encargos que a norma jurídica lhes impõe, tendo em vista o interesse e a proteção dos filhos (DINIZ, 2004). (grifo nosso).

Ademais, a corroboração por dispositivos infraconstitucionais reforça o papel do Estado na preservação da função social da família. Em síntese, registram-se: Estatuto da Criança e do Adolescente - ECA - Lei no 8.069/9o; Estatuto do Idoso - Lei ro.74I/2003; Bolsa Família - Lei no 1o.836/2004; e a Lei Maria da Penha - Lei no Ir.340/2006, os quais serão alvos de sucinta análise.

\subsection{Estatuto da criança e do adolescente - Lei no 8.069/90.}

Não existe revelação mais nítida da alma de uma sociedade do que a forma como esta trata as suas crianças ${ }^{33}$. Considerado um marco histórico, o ECA - Estatuto da Criança e do Adolescente - trouxe para o ordenamento jurídico brasileiro não somente a proteção de direitos fundamentais, mas também definiu as obrigações e deveres nas relações entre Estado, família e juventute. (LEI 8.069, I990)

A partir das diretrizes da Declaração dos Direitos da Criança e das Regras Mínimas das Nações Unidas para administração da Justiça da Infância e Juventude (NAÇÕES UNIDAS, 1995), a lei no 8.069/90, além de levar em consideração aspectos existenciais como saúde, integridade pessoal, emoções, interação e proteção social, hipervulnerabilidade, educação compulsória (art. 22), ela regulamenta a apreensão do adolescente, trata das medidas socioeducativas aplicáveis ao menor infrator e pune o abuso do Poder Familiar nas relações jurídicas entre pais e filhos.

\subsection{Estatuto do idoso - Lei 10.74I/2003}

As distintas fases da vida, as quais todos os seres humanos estão sujeitos, requerem manutenções peculiares às necessidades manifestas ao decorrer da idade. A lei 10.74I/2003 tutela o bem-estar físico e mental da pessoa idosa, fatores fundamentais para a dignidade da pessoa humana (art. I).

\footnotetext{
${ }^{33}$ Frase de Nelson Rolihlahla Mandela. Advogado, líder rebelde e presidente da África do Sul de 1994 à 1999.
} 
Desta maneira, a moral cooperativa intervém por meio da lei, inserindo na sociedade condutas que trabalham a empatia e o senso comunitário, a fim de respeitar a vulnerabilidade destes indivíduos - atendimento prioritário/preferencial (art. 3).

Também, a discriminação, negligência e o abandono decorrentes de um relacionamento familiar disfuncional passaram a ser tipificadas pela lei. $\mathrm{O}$ artigo 98 do Estatuto do Idoso assim estipula:

Art. 98. Abandonar o idoso em hospitais, casas de saúde, entidades de longa permanência, ou congêneres, ou não prover suas necessidades básicas, quando obrigado por lei ou mandado:

Pena - detenção de 6 (seis) meses a 3 (três) anos e multa (BRASIL, 2003).

Dentre os princípios do direito das famílias, destaca-se, portanto, a Solidariedade familiar compulsória, como meio essencial para efetivação da função social da família.

\subsection{Bolsa família - Lei no $10.836 / 2004$}

Enquanto agente mantenedor da função social da família, restou ao Estado a responsabilidade de assistência, viabilizando condições para que as famílias possam atender as expectativas da função social que lhes cabe (art. 2).

Dessa forma, a lei 10.836/2004 possibilitou a garantia de alimentação, acesso à aducação e a saúde, preservando a dignidade dos membros que se encontram em situação de vulnerabilidade em razão da pobreza.

\subsubsection{Lei Maria da Penha - Lei no 11.340/2006}

De acordo com o Tribunal de Justiça do Rio Grande do Sul, a violência familiar e doméstica pode ser tipificada das seguintes formas:

Violência doméstica - quando ocorre em casa, no ambiente doméstico, ou em uma relação de familiaridade, afetividade ou coabitação.

Violência familiar - violência que acontece dentro da família, ou seja, nas relações entre os membros da comunidade familiar, formada por vínculos de parentesco natural (pai, mãe, filha etc.) ou civil (marido, sogra, padrasto ou outros), por afinidade (por exemplo, o primo ou tio do marido) ou afetividade (amigo ou amiga que more na mesma casa).

Violência intrafamiliar / violência doméstica - acontece dentro de casa ou unidade doméstica e geralmente é praticada por um membro da família que viva com a 
vítima. As agressões domésticas incluem: abuso físico, sexual e psicológico, a negligência e o abandono.

Violência contra a mulher - é qualquer conduta - ação ou omissão - de discriminação, agressão ou coerção, ocasionada pelo simples fato de a vítima ser mulher e que cause danos, morte, constrangimento, limitação, sofrimento físico, sexual, moral, psicológico, social, político ou econômico ou perda patrimonial. Essa violência pode acontecer tanto em espaços públicos como privados. ${ }^{34}$

Dessa forma, a lei II.340/2006 entra no ordenamento jurídico brasileiro para combater uma das formas de violência familiar e doméstica que atentam contra a função social da família e a dignidade da pessoa humana.

A Maria da Penha é uma das melhores leis e a maior ferramenta que temos hoje para proteção da dignidade e dos direitos humanos das mulheres. Ela abrange todas as questões da violência - física, psicológica, moral, sexual, patrimonial - além de prever medidas protetivas de urgência para de fato tirar a mulher de uma situação de violência iminente. (TRIPODE, 2020).

É de entendimento pacífico (SOMER, BRAUNSTEIN, 1999) que a violência intrafamiliar afeta a formação psicológica da criança, provocando impactos que, à posteriori, serão identificados no meio social. Mesmo quando as crianças de lares violentos não são o alvo direto do abuso, frequentemente são envolvidas na violência de seus pais de outras formas que as colocam em risco (FANTUZZO, ET AL, 1997).

A política de combate à violência contra a mulher, portanto, apresenta um viés duplo de preservação da dignidade da mulher e da manutenção da função social da família.

\section{METODOLOGIA}

A abordagem qualitativa e a técnica de análise por meio da pesquisa bibliográfica, somadas à avaliação histórico-social, bem como ao estudo dos dispositivos legais (tanto nacionais e internacionais), possibilitaram a conclusão deste trabalho.

A pesquisa por raciocínio dedutivo pautada na tese tema deste artigo, trabalha a relação entre o Estado, a família e o indivíduo de forma a verificar as evidências de que o seio familiar influencia na sociedade, dado o fato de ser a primeira experiência social do

\footnotetext{
${ }^{34}$ Coordenadoria Estadual da Mulher em Situação de Violência Domestica e Familíliar do Tribunal de Justiça do Rio Grande do Sul. Tipos de Violência Doméstica e Familiar

Portal Brasil. Porto Alegre/RS. Disponível em: (<https://www.tjrs.jus.br/novo/violenciadomestica/orientacoes/tipos-de-violencia-domestica-e-familiar/ ). Acesso em: II de outubro de 2021.
} 
indivíduo. O percurso metodológico originou-se a partir da leitura dos livros de Jean Bolen Shinoda: O Anel do Poder; e Carta ao Pai, de Franz Kafka. A avaliação crítica jurídica tomou forma por meio dos doutrinadores Dimas Messias de Carvalho, Lucas Calderón.

Com a base fundamentada nestes doutrinadores, outros foram necessários para a composição dos argumentos presentes ao longo do trabalho. Jean-Jacques Rosseau, Clóvis Bevilaqua, foram componentes essenciais para as considerações realizadas ao final.

\section{ANALISE E DISCUSSÃO OU INTERPRETAÇÃO DE RESULTADOS}

Em primeira análise, verificamos que nos antecedentes da legislação civil brasileira, a função social da família era zelar pela imagem pública do indivíduo, bem como garantir a perpetuação do patrimônio no nome da família, fatores estes tutelados pelo Estado.

Em seguida, após uma breve estudo do conceito de família, observamos a formação de um ciclo vicioso onde a sociedade influencia neste instituto, que torna a influenciar na sociedade. Concluimos trata-se de uma comunidade que sofre efeitos da Sociedade a qual está inserida, tais efeitos dependem do contexto histórico, geográfico e jurídico.

Prontamente, identificamos a importância dos princípios jurídicos, sobretudo como fonte de Direito. Depreendemos como consequência, a imprescindibilidade de sua aplicação na interpretação das normas, em razão de seus aspectos jurídicos e morais.

Em atenção às relações sociológicas, no que tange a formação do núcleo familiar, e às características psicossociais decorrentes destas, constatamos que é na família onde forma-se o mais íntimo traço da personalidade de um indivíduo, pois nela origina-se a subjetividade, componente que molda as ações do indivíduo. Em consequência, constatou-se que cabe ao Estado orientar e corrigir as relações familiares por meio do Direito.

Por conseguinte, identificamos na Convenção do direito das crianças a busca pela efetivação da função social da família no ambito internacional. Pautada em valores morais aceitos universalmente, a convenção é vista como uma das mais eficientes formas de concretização dos Direitos Humanos, pois trata de elementos como a assistência social, tráfico de crianças, prostituição e pornografia infantil, envolvimento de crianças em conflitos armados e outros.

Em breve análise aos estudos comparados, entendemos a difícil tarefa que é a concretização dos Direitos fundamentais no incerto solo da função social da família na 
esfera internacional, uma vez que sua efetividade depende da adequação cultural e compreensão social.

Ademais, em razão do supracitado, nos deparamos com um ponto controverso passível de futuras análises mais profundas: deveria o Estado contentar-se com o seu próprio desenvolvimento em função da integridade psicológica de seus integrantes?

Em última observação, avaliamos a influência do princípio da função social da família na legislação brasileira, bem como a sua importância para o desenvolvimento do Estado democrático de direito.

\section{CONSIDERAÇÕES FINAIS}

Ainda que notória a presença de certas lacunas - dado que o estudo das relações humanas não serão satisfeitos sob uma única visão acadêmica - ponderamos que os objetivos propostos para a realização desta pesquisa, isto é, explanar sobre o princípio da função social da família e a sua importância para o desenvolvimento do Estado democrático de direito, foram atingidos da forma desejada.

Constatamos que a evolução moral viabilizou a reestruturação de um ordenamento jurídico cujas políticas familiares destacaram-se internacionalmente a partir de dispositivos infraconstitucionais que reforçaram o papel do Estado enquanto agente mediador das relações e garantidor de direitos fundamentais.

Deduziu-se também o papel exemplar do Brasil no que tange a criação de políticas que viabilizem a efetivação dos Direitos Humanos e, em consequência, da função social da família. Ainda que a realidade deixe a desejar, observamos que mesmo os países mais desenvolvidos enfrentam problemas em atingir tal concretização.

A investigação por meio do raciocínio dedutivo, abordagem qualitativa e pesquisa bibliográfica; a breve análise histórico-social, somada a consulta à legislação nacional e internacional, bem como a leitura de produções acadêmicas, mostraram-se satisfatórias para o entendimento almejado.

Por meio da avaliação crítica e baseado nos dados expostos no corpo deste trabalho, depreendemos que há fortes evidências que o seio familiar influencia na sociedade, dado o fato de ser a primeira experiencia social do indivíduo. Dessa forma, conclui-se que esta 
pesquisa se satisfez em sua essência, uma vez que ampliou a compreensão acerca do tema e insurgiu novas perspectivas que podem e devem ser debatidas em análises ulteriores.

\section{REFERÊNCIAS}

ALVES. João Eudes do Nascimento. CONDUTA DE PAIS, CAMINHOS DE FILHOS: CONFLITOS FAMILIARES NA CIDADE DA BAHIA (I779-1799). Dissertação de Mestrado apresentada ao Programa de Pós-Graduação em História, do Centro de Humanidades da Universidade Federal de Campina Grande. Campina Grande, 2020.

ALMEIRA. Candido Mendes. Ordenações e leis do Reino de Portugal. Ed.I4. Rio de Janeiro. Disponível em: (https://www2.senado.leg.br/bdsf/item/id/242733). Acesso em: 26 de julho de 202I.

BEVILAQUA, Clovis. Direito da família. 3. ed. São Paulo: Red Livros, 20oI

BRASIL. Código de Processo Civil. Planalto. 2015. Acesso em: http://www.planalto.gov.br/ccivil_03/_ato2015-2018/2015/lei/li3105.htm

BOLEN, Jean Shinoda. O anel do poder. Editora Pensamento Cultrix, 2020.

BRASIL. Brasília, Senado Federal, 1988. Disponível em: (http://www.planalto.gov.br/ccivil_03/constituicao/constituicao.htm). Acesso em: or de setembro de 202I

BOCK, Ana Maria Bahia; FURTADO, Odair; TEIXEIRA, Maria de Loudes Trassi. Psicologias: uma introdução ao estudo de psicologia. São Paulo: Saraiva, 2005.

B. Shaw Drake. C. Megan. U.S. Stands Alone: Not Signing U.N. Child Rights Treaty Leaves Migrant Children Vulnerable. Huffpost, 2016. Disponível em: https://www.huffpost.com/entry/children-migrants-rights_b_8271874. Acesso em: 04 de outubro de 2021.

BBC NEWS, 2015. Disponível em: https://www.bbc.com/portuguese/noticias/2015/07/150705_japao_suicidio_rb. Acesso em: 04 de outubro de 2021.

BLUEVISION, 2018. Disponível em: https://bluevisionbraskem.com/desenvolvimentohumano/joshua-greene-a-moral-e-uma-poderosa-ferramenta-da-evolucao-humana/ Acesso em: 04 de outubro de 2021.

BRASIL. Convenção sobre os Direitos da Criança, 1990. Disponível em: https://www.unicef.org/brazil/convencao-sobre-os-direitos-da-crianca. Acesso em: o4 de outubro de 202I

CERVENY, Ceneide Maria de Oliveira. A família como modelo: desconstruindo a patologia. São Paulo: Livro Pleno, 2000 


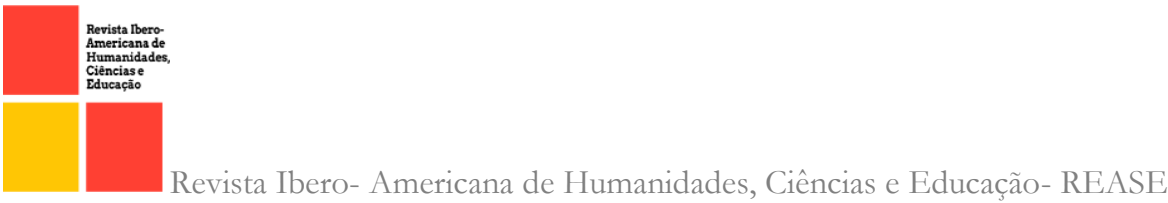

CARVALHO. Dimas Messias de. Direito das Famílias. 7. Ed. São Paulo. Saraiva, 2019.

CARVALHO, Francisco José. A função social do Direito e a efetividade das Normas Jurídicas. Disponível em: http://www.cartaforense.com.br/ conteúdo /artigos/a-funcaosocial-do-direitoea-efetividade-das-normas-juridicas/7940. Acesso em: 22 de setembro de 2021

Convention on the Rights of the Child. Guidelines regarding the implementation of the Optional Protocol to the Convention on the Rights of the Child on the sale of children, child prostitution and child pornography. Original: English. Disponível em: https://www.ohchr.org/en/professionalinterest/pages/opsccrc.aspx. Acesso em: 3 de novembro de 2021.

Convention on the Rights of the Child. DRAFT Guidelines on the implementation of the Optional Protocol to the Convention on the Rights of the Child on the sale of children, child prostitution and child pornography. I996-202I. Disponível em: (https://www.ohchr.org/EN/HRBodies/CRC/Pages/DraftGuidelinesOPs.aspx). Acesso em 25 de outubro de 202I.

Convention on the Rights of the Child. Japan's Comments on the Draft Guidelines on the implementation of the Optional Protocol to the Convention on the Rights of the Child on the sale of children, child prostitution and child pornography. Disponível em: (https://www.ohchr.org/EN/HRBodies/CRC/Pages/DraftGuidelinesOPs.aspx). Acesso em 25 de outubro de 2021.

Código Civil Japonês, 26 de junho de 2019, primeiro ano de Reiwa. Disponível em: http://www.japaneselawtranslation.go.jp/law/detail/?ft $=2 \& \mathrm{re}=02 \& \mathrm{dn}=\mathrm{I} \&$ yo $=$ civil + code $\&$ $\mathrm{x}=\mathrm{I} 4 \& \mathrm{y}=\mathrm{I} 2 \& \mathrm{ia}=03 \& \mathrm{ja}=04 \& \mathrm{ph}=\& \mathrm{ky}=\&$ page $=3$. Acesso em: I9 de novembro de 202I.

Código Penal Japonês, 26 de junho de 2019, primeiro ano de Reiwa. Disponível em: http://www.japaneselawtranslation.go.jp/law/detail/?ft $=2 \& \mathrm{re}=02 \& \mathrm{dn}=\mathrm{I} \& y o=$ civil + code $\&$ $\mathrm{x}=\mathrm{I} 4 \& \mathrm{y}=\mathrm{I} 2 \& \mathrm{ia}=03 \& \mathrm{ja}=04 \& \mathrm{ph}=\& \mathrm{ky}=\&$ page $=3$. Acesso em: I9 de novembro de 202I.

DELGADO, Maurício Godinho. Curso de direito do trabalho. - ıo ed. São Paulo: LTr, 2oII, p.I8o.

DINIZ, Maria Helena. Código Civil Comentado. ıo a $^{\mathrm{a}}$. São Paulo: Saraiva, 2004.

DIAS, Maria Berenice. $O$ Direito à Felicidade. Disponível em: http://www.berenicedias.com.br/manager/arq/(cod2_553)o_direito_a_felicidade.pdf.

Acesso em: 25 de outubro de 2021.

Escolas Pelo Mundo. Notícias: Transformando.com.vc, is de julho de 2021. Disponível em: https://transformando.com.vc/escolas-pelo-mundo-conheca-como-e-a-educacao-nojapao/. Acesso em: 02 de dezembro de 2021. 
Fantuzzo JW, Boruch R, Beriama A, Atkins M, Marcus S. Domestic violence and children: Prevalence and risk in five major U.S. cities. Journal of the American Academy of Child and Adolescent Psychiatry 1997;36(I):116-I22.

FARIAS, Cristiano Chaves de. et. al. Código Civil para concursos: doutrina, jurisprudência e questões de concursos - 5. ed. Salvador: Juspodivm, 2017

FIGUEIREDO. Sabrina de Oliveira. Desestruturação familiar e criminalidade juvenil: reflexões sobre uma possível relação à luz de abordagens interdisciplinares. Disponível em: (https://jus.com.br/artigos/79709/desestruturacao-familiar-e-criminalidade-juvenil).

Acesso em: i9 de Setembro de 2021.

G. Por que o Japão tem uma taxa de suicidio tão alta? 2015. Disponível em: (http://gi.globo.com/mundo/noticia/2015/o7/por-que-o-japao-tem-uma-tadesuicidiostaoalta.html). Acesso em: 04 de outubro de 2021.

HUMANIUM. Geneva, 2008. Disponível em: https://www.humanium.org/en/unitedstates-of-america/. Acesso em: 27 de outubro de 202I.

IES, 202I. Disponível em: https://culturalatlas.sbs.com.au/japanese-culture/japaneseculture-family. Acesso em: 04 de outubro de 2021.

JAPÃO. Centro de Educação e Pesquisa da Universidade Farmacéutica de Kyoto. Original: Education and Research Center for Clinical Pharmacy, Kyoto Pharmaceutical University. Japão, 2003.

KAFKA. Franz. A Metamorfose; Um Artista da Fome; Carta a meu Pai. Coleção a Obraprima de cada autor, texto integral. Editora Martinn Claret, São Paulo. 2004.

LINDB (Lei de Introdução as Normas do Direito brasileiro). Redação dada pela Lei no 12.376/ı. Brasília, Senado Federal, 2oro. Disponível em: (http://www.planalto.gov.br/ccivil_03/decreto-lei/del4657compilado.htm). Acesso em: 31 de agosto de 2021

LOURO, Guacira Lopes. Gênero, Sexualidade e Educação: uma perspectiva pósestruturalista. Petrópolis, Vozes, 1997 e Pedagogias da Sexualidade.

Lições Preliminares de Direito. 19 ${ }^{a}$ ed., São Paulo: Saraiva.ı91. p. 299.

MOTOHASHI, Hydeyuki. FUJIMOTO, Atsuko. SAKANE, Toshiyasu. YAMAMOTO, Yano. YANO. Social factors of mental disorder and suicide in Japan-for understanding circumstance of suicides in each prefecture. Yakugaku Zasshi.

MONTEIRO, Washington de Barros. Curso de direito civil: Direito de Família. 37. ed. São Paulo: Saraiva, 2004.

MIATELLO. André Luis Pereira. Relações de poder e bem comum na Baixa Idade Média italiana (séc. XIII-XIV). Anos 90, Porto Alegre, v. 20, n. 38, p. 181-217, dez. 2013.

MELlO, Celso Antônio Bandeira de, Curso de Direito Administrativo. I2 - ed. - São Paulo : Malheiros, 200o, p. 747/748. 
ONU, 2015. Disponível em (https://brasil.un.org/pt-br/69412-onu-com-adesao-do-sudaodo-sul-apenas-eua-nao-ratificaram-convencao-sobre-os-direitos-das). Acesso em: 04 de outubro de 2021.

ONU. 24 de outubro de 1945. Disponível em: (https://www.un.org/en/about-us/historyof-the-un). Acesso em: i9 de setembro de 2021.

OPAS/OMS. Depressão. Escritório Regional Para as Américas da Organização Mundial da Saúde. Representação das OPAS e da OMS no Brasil. Disponível em: https://www.paho.org/pt/topicos/depressao. Acesso em: 27 de outubro de 2021.

ROUSSEAU. Jean-Jacques. Emílio ou Da educação. Tradução: Sérgio Milliet. São Paulo: Difusão Europeia do livro, 1973.

ROUSSEAU, Jean-Jacques. Contrato Social. Tradução: Lourdes Santos Machado, São Paulo: Nova Cultural, Coleção Os Pensadores, vol. I, 2000.

ROUSSEAU, Jean-Jacques. Discurso Sobre a Origem e os Fundamentos da Desigualdade Entre os Homens. Tradução: Lourdes Santos Machado, São Paulo: Nova Cultural, Coleção Os Pensadores, vol. II, 2000.

ROSA, Conrado Paulino da. iFamily: um novo conceito de família? São Paulo. Saraiva, 2013. REALE, Miguel. Função social da família no Código Civil. O Estado de São Paulo (São Paulo - SP) em II/ Io/2003

RENAUT, A. A Libertação das crianças: a era da criança cidadão. Lisboa: Instituto Piaget, 2002.

SANTOS. Maria Beatriz. MATTOSO. Agda. "Produtividade e o lado positivo da vida que adoece". São Paulo, 2020.

SMANIOTTO. Melissa Andréa. FILHO. Nei Alberto Salles. UMA RELEITURA DA FUNÇÃO SOCIAL DA FAMÍLIA A PARTIR DA PERSPECTIVA CRÍTICA DOS DIREITOS HUMANOS. Revista de Ciências Humanas e Sociais - v.6, n. 3, ed.especial. 2020.

SOMER. Braunstein A. E. Are children exposed to interparental violence being psychologically maltreated? Aggression and Violent Behavior 1999. P. 449-456.

SANTOS. Maria Beatriz. MATTOSO. Agda. "Produtividade e o lado positivo da vida que adoece". Terapia Clínica SP. São Paulo, 2020. Disponível em: ( $\langle$ http://terapiaclinicasp.com.br/produtividade-e-o-lado-positivo-da-vida-que-adoece/ $>$ ). Acesso em: o6 de outubro de 202I.

The Washington Post, 2014. Disponível em: https://www.washingtonpost.com/blogs/post-partisan/wp/20I4/II/2I/why-wont-the-us-ratify-the-u-n-s-child-rights-treaty. Acesso em: 04 de outubro de 2021.

The Japan Times, 2021. Disponível em: (https://www.japantimes.co.jp/news/2021/oI/13/national/domestic-violence-casesrecord-high/) Acesso em: 04 de outubro de 202I. 
TRIPODE. Mariana. Revista Consultor Jurídico, 3 de setembro de 202I. Disponível em: (https://www.conjur.com.br/202I-set-03/tripode-convencao-belem-violencia-genero). Acesso em: II de outubro de 202I.

TEIXEIRA, Ana Carolina Brochado; RODRIGUES, Renata de Lima. O direito das famílias entre a norma e a realidade. São Paulo. Atlas, 2010.

VERONESE. Josiane Rose Petry. Direito da Criança e do Adolescente da Universidade Federal de Santa Catarina. Medidas sócio-educativas: sinônimo de Pena?. Âmbito Jurídico, Volume V. Florianópolis, 2012. 